\section{BIOENGINEERING}

\section{Catch-all or Cornucopia?}

from a Correspondent

THE two faces of bioengineering were clearly displayed during the symposium held from June 19 to 21 at the University of Strathclyde, Glasgow.

Half of the programme was devoted to biomechanics - the application of engineering principles and techniques to the study of human bones, joints and tissues. Much of this work is at an early stage, involving experiments on animals or on post-mortem material, but direct measurements of pressures in the spine (using an implanted transducer with radio telemetry) reported by Professor A. Nachemson and Dr G. Elfström (University of Gothenburg) are beginning to give useful information on the treatment of patients with low back pain and on post-operative management after bone surgery.

Dr C. A. McLaurin (Ontario Crippled Children's Centre, Toronto) considered that biomechanics is still an academic discipline of little value to the clinician. $\mathrm{He}$ offered two reasons for this failure. First, the human body does not resemble a man-made machine; most machines are designed to suit the engineering principles on which they are based-but the mechanical principles of the body are not yet understood. Second, said Dr McLaurin, the patient management process does not lend itself to systematic method. Doctors have little patience with the promise of biomechanics, because they work in clinics where problems must be analysed and sometimes found in a matter of minutes. He urged that biomechanics should be brought closer to reality by the greater involvement of practising members of the medical and remedial professions.

Professor D. Dowson and Professor V. Wright (University of Leeds) reported that the remarkably effective mechanism for the lubrication of loadbearing joints still defies analysis in engineering terms. Attempts to treat stiff joints by the injection of silicone or other artificial lubricants have not been successful.

A session on artificial organs was dominated by the views of $\mathrm{Mr} D$. Longmore (National Heart Hospital, London) who suggested that 75 per cent of patients with chronic kidney failure die unnecessarily because of lack of renal dialysis facilities - a situation which he described as "murder by neglect". He thought that artificial kidney treatment would be better provided by mobile units, based on double decker buses, which would visit hospitals.

Mr Longmore dismissed current research towards the replacement of the ailing heart by a mechanical pump as largely wasted effort, through lack of clear medical leadership and achievable specifications. Acknowledging that heart transplants were at present unacceptable to society he suggested that more attention should be given to other biological treatments; tissue affected by a myocardial infarct might be revascularized by an implant of foetal heart tissue.

The symposium confirmed the view, expressed by several speakers, that bioengineering has not yet made much impact on the clinical scene. The most successful work has been done in biomechanics; excursions into physiology or medical physics have often been unproductive or unconvincing.

\section{OCEANIC FISHES}

\section{Biology of Bramids}

from our Marine Vertebrate Correspondent THE bramids are an oceanic family of fishes with a worldwide distribution except for the polar seas. Many species have been described, but a recent revision by $\mathrm{G}$. W. Mead (Dana Report, No. 81,$1 ; 1972$ ) reduces them to eighteen species in six genera. Mead's revision will be welcome to taxonomists in particular, but fisheries biologists will also welcome it because it clears away some of the dead wood of nomenclature in the group.

The reason for the plurality of names in the group is in the main two-fold. First, many of the species are moderately large when full grown, some even reach- ing a metre in length, and have thus engaged the attention of biologists from the earliest times (the earliest record of a bramid in the literature seems to be the specimen of Brama brama described by John Ray in 1686). Second, the young fish are often totally dissimilar to the adults in body shape and other features. A third and complicating factor lies in the relatively few specimens in marine collections.

Mead's revision has been made possible by the use of the vast collections of young fish in the Danish Carlsberg Foundation, made by the research vessel Dana, supplemented by museum collections. A most useful additional source has been supplies of juvenile fish taken from the stomachs of tuna and billfishes, predators that seem able to catch the size of fish that nets and hooks miss. Possession of long series of larval and juvenile specimens as well as adults has meant that it has been possible to link known juvenile forms with known adults, allometry notwithstanding. This is obviously of importance to fishery biologists who are concerned to explore the food chains of the valuable and commercially exploited tunas.

Several bramids are directly exploited as food by man. One such fishery off the western and northern coasts of Spain for Brama brama is locally important, the bramids being captured on long lines set some 18 to 25 miles offshore. The catch is marketed locally fresh or canned for use elsewhere in Spain. It is this species which from time to time makes an appearance in the waters of

\title{
Messenger RNA Inactivation
}

ONE of the diagnostic characteristics of messenger RNAs in bacteria is that they are labile and compared with ribosomal or transfer RNAs have very short half lives. For more than a decade, however, since this fact was established the molecular basis of the instability of messenger RNA has remained an enigma. To be sure various ribonucleases have been discovered and tentatively implicated in mRNA decay, and the four obvious possible mechanisms of messenger degradationnamely that these molecules are degraded from one or both ends or internally at any position or at specific sites-have had their supporters, but the issue is still unresolved.

One of the problems, as Blundell, Craig and Kendall point out in next Wednesday's Nature New Biology (July 12), is that different bacterial strains and different growth conditions have been used by groups measuring the kinetics of turnover of this or that messenger, and not surprisingly the resulting data are disparate.

By measuring the loss of activity of enzymes specified by the lac and tryp operons, and indirectly, therefore, measuring the turnover of the messengers of these operons, in the same Escherichia coli cells, Blundell et al. have at least avoided this unnecessary complication. And by exploiting various deletion mutants they have measured the half lives of shortened messenger molecules. Their experiments reveal two important characteristics of messenger inactivation; first, different species of messengers are inactivated at different rates and, second, within one polycistronic RNA the different cistronic messages are also inactivated at different rates.

From these and other findings the group concludes that the most satisfactory model of the inactivation of messenger RNAs ascribes to each cistronic region of a polycistronic messenger a certain limited number of sites vulnerable to nucleolytic attack. Blundell et al. hope that by using the many deletion mutants of the lac operon it may be possible to identify these target sites. 